\title{
3. Gendered Hierarchies of Knowledge and the Prestige Factor: How Philosophy Survives Market Rationality
}

\author{
Fiona Jenkins
}

\begin{abstract}
Neoliberalism - a term now used only by critics - evokes the absorption of the erstwhile social state into a corporate culture. The purported minimisation of the scope of political power corresponds to the ascendency of economic man, characterised by entrepreneurial spirit, individualism, flexibility, and adaptability. Appeals to economic rationality and practical constraints, and the use of words like 'performance', 'efficiency', 'mobility', 'competitiveness' and 'evaluation', cast mockery at institutions modelled on solidarity, social security, justice or the substantive values of democracy. What lacks market value also lacks the right to exist. The university, to survive, must engage in benchmarking, marketing; seek public-private partnerships; generate profits; incentivise its employees; and offer up its technocratic expert knowledge, as evidence of its co-operative participation in presumptively necessary processes of change.
\end{abstract}

Given that this shapes the framework of evaluation of all aspects of intellectual endeavour, how does it impact a discipline like philosophy? My interest here is first in how, given a core conception of its nature and value, institutional philosophy might survive within this market framework; and second, at what price, in terms of its ongoing commitment to the correspondingly devalued realms of merely 'social' concern. In particular, I would like to try to track some inter-relations between the following points: (a) how certain defining but also competing 'internal' conceptions of the discipline might be regarded as adapting themselves to the spirit of the times (involving answering in a particular way key problems endemic to the discipline; for instance, about how philosophy orientates itself to truth, or the nature of reason that it properly 
embodies); (b) how the dominance of one or other such conception carries with it implications for gender relations within the discipline; and thus (c) how the particular sorts of social ends marked by feminism fare within the terms provided by the project of disciplinary survival in the neoliberal academy. If I speak of 'survival', it is because philosophy on the face of it lacks the marketdefined right to exist; and yet one could also remark that at least some parts of institutional philosophy have in fact flourished under the competitive systems introduced in the university sector to mimic market-driven rationality - notably via the discourse of 'excellence' and the logic of rankings.

Again, my question about these terms of flourishing will be: at what price for feminist projects, both in intellectual terms and in terms of seeking equality? The adaptations contemporary feminism has made to market conditions also need to be considered here. It is important to note that much of the current push to redress overwhelming male dominance in all areas of university leadership and the severe underrepresentation of women in certain areas (notably the Science, Technology, Engineering and Mathematics (STEM) disciplines) frames itself as an appeal to economic and performance-based concerns. Thus contemporary arguments for gender equality have to a significant extent ceased to be framed as arguments for social justice and have instead become framed as arguments for economic efficiency. Again, the aspect of this I will be interested in is how this way of framing equality intersects with conceptions of disciplinary integrity, and the relation between the pursuit of knowledge and the pursuit of social justice. The case of philosophy is interesting because the levels of underrepresentation of women are like STEM disciplines, yet it is unclear what kind of parallel arguments could be made about the economic importance of including women, given the non-self-evident economic value of the discipline itself.

No doubt there is a very complex story to be told about how market rationality and the means of taking advantage of it, has impacted and fostered the gendering of knowledge and the status of epistemic agents. Here I try to sketch what just a few aspects of that story might look like in one discipline and to use it as a lens for asking from a feminist perspective how to evaluate the kinds of change we are seeing in universities.

\section{Philosophy and the market}

The question of what is 'proper' to philosophy is repeatedly staged at its very inception. If Socrates taught in the marketplace or agora, he as surely defined the practice and orientation of philosophy in terms that defied market values. Mere Sophists sold their intellectual wares to the highest bidder, and taught 
skills in rhetoric and argumentation that would serve a man in the business of politics or in the courts. But Socrates sought to teach a virtue or 'excellence' of knowledge that would transcend such instrumental ends. Without participating in practical affairs, Socrates aimed at politics in the highest sense, as institutional arrangements based in justice and truth; and his gadfly provocations to authority come down to us in history as the emblem of all that academic freedom should mean. Plato's opposition to the Sophistic mode of education resting on what we would now call 'consumer demand' forms a background to many of the dialogues, including the Theaetetus, which in concerning itself with the question 'what is knowledge?' specifies philosophy's difference from any other discipline. These are engaged with object-oriented types of knowledge, while philosophy examines knowledge as such. Philosophy is this way receives a definition as the mode of inquiry that transcends all others and could be used by Kant to define the very meaning of the modern university, over which philosophy presided as the 'Queen of the Sciences' (Readings 1986, 56). Although such pretensions have surely been humbled, and much in philosophy today has diversified, we still have undeniably core areas that stand for this task, and wrestle with the broad questions Socrates raised. Epistemology, for instance, still asks whether knowledge can be defined as justified true belief, or how to mark the difference between believing correctly and really knowing; and defending the objectivity of knowledge against an array of threatening relativisms, remains a defining philosophical motif or manifesto for its defence. ${ }^{1}$

The ideals expressed in the Socratic paradigm might in this way form a tempting object of nostalgia in times when universities find themselves squeezed into the frameworks of market rationality, and disciplines like philosophy seem doomed to fit their wares to the servicing of ethics committees, or to delivering the vaguely rendered marketability of 'critical skills' to employers. Yet although one aspect of the survival of such venerable ancient disciplines may indeed involve these kinds of adaptation to the spirit of the times, philosophy might also exemplify the capacity to play the system in another way, by occupying the 'elite' status connoted precisely by the pursuit of disinterested, abstract and non-instrumental thought. Perhaps, indeed, such extra-economic sites remain a key component in neoliberalism, securing the vital relationship between raw

1 Here is Todd Edwin Jones (2011), for instance, responding to the closure of the Nevada philosophy department by defending philosophy from the ignorance of those hostile to it, just as Plato sought to do, and claiming the role of first discipline: 'People think of philosophy as a luxury only if they don't really understand what philosophy departments do. I teach one of the core areas of philosophy, epistemology: what knowledge is and how we obtain it. People from all walks of life - physicists, physicians, detectives, politicians - can only come to good conclusions on the basis of thoroughly examining the appropriate evidence. And the whole idea of what constitutes good evidence and how certain kinds of evidence can and can't justify certain conclusions is a central part of what philosophers study. Philosophers look at what can and can't be inferred from prior claims. They examine what makes analogies strong or weak, the conditions under which we should and shouldn't defer to experts, and what kinds of things (e.g. inflammatory rhetoric, wishful thinking, inadequate sample size) lead us to reason poorly.' 
market values - what one can buy and sell - and the privileged and authoritative status of elite universities, the 'top 100' whose economy of judgments must wield the prestige to structure scales of value that flow downstream into the academic 'market' in the form of journal rankings, esteem ratings, etc. ${ }^{2}$

Here another take on what the implementation of neoliberal policies has meant within universities, and in particular ways at disciplinary level, may be necessary. Part of the violence at work in introducing neoliberal reforms stems from how they re-negotiate, displace or reverse relations of ends and means, or of what serves whom, in ways that re-articulate the proper names of the parties involved and the nature of their transactions. For instance, the university which was once supported by the state to serve the ends of society, is now a site of state investment, offering returns by way of outputs contributory to growing the economy; if students once came to learn subjects like philosophy for the intrinsic benefits of doing so, they now are encouraged to study at tertiary level primarily in order to buy a training that puts them individually at competitive advantage in the graduate job market, making them into paying customers for the university's goods. But within what might seem the simple imposition of market values lurk fundamentally political relations. In this context who serves whom, and thus what constitutes a means and what an end, are questions inseparable from relations of dominance and subordination, and indeed the rights of judgment. Who is answerable to whom? Who or what is judged to be of value and by what right? One characteristic of this field of power as it impacts the university is that to gain the upper hand in determining the subordination of the end of 'pure knowledge' to economic instrumentation, forms of generalised judgment (most often the discourse of 'excellence') are instituted that at once incorporate and transcend, distort and preserve academic judgment. These terms of 'excellence' thus provide scope, paradoxically, to lay claims within the 'market-driven' rationale to occupy the position of the idealised and neutral judge, able to survey a field that is given under a certain definition (for instance, via a disciplinary name) as if all contestation over what constitutes that field can be dealt with by hierarchically ranking 'core' and 'sub-disciplinary' concerns. Certain epistemic convictions, or put differently, the symbolic status afforded to certain epistemic convictions will prove more conducive to occupying this position than others. Thus for instance, if as is the case for many feminist philosophers, one is persuaded by one form or another of argument for a standpoint-based epistemology, one will be less well-

2 As noted by Corbett et al. (this volume): 'Prospective funding agencies are drawn not just to the reality of independent analysis, but also the perception and prestige of independent analysis, for the powerful legitimating benefits this can bring to their intramural policy battles within the government sector as well as their efforts to lead public thinking on particular issues.' My argument is that this may be of broader importance within the trajectories of disciplines themselves. 
suited to occupy the position of neutral judge than someone who believes in - and publishes extensively in the 'top' journals about - an epistemic position supportive of abstract ideals of objectivity.

As purveyors of academic judgment, as well as individual practitioners of career entrepreneurship, academics contribute to generating the hierarchies of institutions, faculties and journals that secure investment for some, and dis-investment for many. It would be wrong to suppose that the academic politics of defining values plays no part in this production of 'excellence', but this is always intertwined with negotiation and dispute over values intrinsic to disciplinary character: there is thus competition between the ideals and values held by diverse disciplinary practitioners, together with the struggle to secure disciplinary status, within long historical traditions that can be invoked to legitimate self-conceptions that are nonetheless also highly adapted to the spirit of the times. To be able to lay claim to practise a discipline of exemplary epistemic integrity, one that concerns itself with 'knowledge as such' may seem suicidal in a market-defined context; yet insofar as this is a quality-defining value, the prestige it carries may be worth far more than anything that is merely available for exchange.

It is broadly within these terms that I would explain how it is that philosophy or at least, as I shall come to, the right type of philosophy - has not done nearly as badly as one might expect. Under prevailing models of the 'purpose' of universities, and of the public and private goods they should serve, philosophy readily looks to be fairly useless; ${ }^{3}$ and despite there being stories to be told about how philosophy contributes to society, and particularly in contexts where it is 'applied' in various ways, ${ }^{4}$ when asked to specify the 'national importance' of a conventional philosophical project on an ARC application, or to weigh one's 'impact' outside the academy, it is possible - I can testify - to feel some despair. Yet for some, this despair would be misplaced. In certain incarnations, philosophy seems to be much better able to survive market pressures than any simple picture

\footnotetext{
3 In the last days of the 2013 Australian Federal election, the then Leader of the Opposition Tony Abbott undertook an assault on the futility of three named research projects, two of which were in the field of continental philosophy. It is significant for my argument that these projects were in an area of research in philosophy that is not mainstream in Anglophone philosophy, and is therefore perhaps particularly vulnerable (Benson 2013).

4 See Peter Bowden responding to department closures by exhorting philosophers to meet the imperative to both educate and train by offering their skills in ethics throughout the university. 'Philosophy has failed dismally to train teachers, as it has failed to develop researchers in moral practices across the other academic disciplines. The educational literature from each of these professions demonstrates the great variety of ethics courses that has resulted from this DIY approach. The diversity is truly amazing, ranging from courses that have no moral educational content at all, to courses that are a little more than an adaptation of a history of ethics course from a department of philosophy. The blame lies with philosophers. There are virtually no training programs in the schools of philosophy for people who want to teach ethics in other disciplines. More worrying, there are very few training courses for people who have to resolve ethical issues and establish ethical practices in the workforce. As the mother discipline, this need can only be satisfied by a school of philosophy.'
} 
of how its 'value' could be reduced to market formulae might lead one to suppose. The discipline has done very well under models of 'research excellence', since 'excellence' constitutes its own special market, bridging between disciplinary and global forms of competition. In New Zealand, Philosophy has been ranked as the highest performing discipline under ERA-type ratings PerformanceBased Research Fund (PBRF) and it does exceptionally well in Australia and the UK too. This in part reflects such factors as a well-developed system of peer review, equally well-developed international networks, with collegial patterns of mutual citation especially strong in certain fields. It transpires that the way to address the question of 'national importance' is most likely to be in terms of one's project's claims to enhancing Australia's academic prestige, by contributing to a field in which one may claim international recognition. But supporting this capacity to deliver a solid validation regime there is also, as I shall go on to argue, an increasingly well-established hierarchy in the kinds of questions philosophy properly addresses, organised by a gendered distinction between 'hard' and 'soft' ends of the discipline.

Before coming to this point, however, I should place it in the context that interests me here; namely, that women do not on the whole do well in philosophy (Hutchison and Jenkins 2013). To give an indicative sample of data, in Australia, according to data collected by the Australasian Association of Philosophy (AAP), women held only 28 per cent of continuing positions in philosophy in 2009, and there is extreme vertical segregation, with around 10 per cent female professors (only two of these few at Go8 universities) (Bishop 2013). There has been little change in the gender composition of the discipline since the early 1990s. From the USA, which has a similar picture, Haslanger shows that women generally are disproportionately underrepresented at elite institutions, and that publishing patterns can be analysed to show that what are deemed the 'top' 20 journals publish articles by women at rates significantly lower than even the levels of women who have made it into tenure at elite universities (Haslanger 2008). And to give another sort of indicator, it is worth noting that during the period of the rise of PBRF, between July 2005 and April 2013, New Zealand departments appointed 20 men and just one woman to positions in philosophy. The one woman was appointed to a 0.5 position, while just four of the 20 men were also appointed to fractional positions. Although this clearly constitutes a very small sample, it invites speculation on how exercises like the PBRF or ARC measure excellence, potential, productivity and employability, in ways that are not merely entrenching but badly exacerbating gender differentials (Rini 2013).

The gendering of knowledge as 'hard' versus 'soft' finds ample expression in philosophy as an element in composing rankings of excellence, facilitating the way that certain fields of inquiry - both those practised in the majority by men, and associated, for wider reasons, with masculinity - are coded as being more 
worthy than others. Thus the 'hard' end of philosophy (logic, epistemology, metaphysics, as well as specific fields of ethical and socio-political inquiry that can be classed as engaged in suitably 'meta'-level theoretical activity) successfully poses as more estimable in its achievements in part because of the way in which it seems able to stand for a particular pure, rigorous and quasiscientific inquiry, unsullied even by deference to the practical outcomes of science. Meanwhile applied aspects of philosophy, feminist theory, anything non Anglo-centric, as well as most historical interests or anything we might class as 'critique', in disciplinary terms all occupy lower tiers. ${ }^{5}$ If the gendered dimensions of this hierarchical ordering to some degree correspond to actual distributions of men and women across the fields of philosophy (there do seem to be far fewer women in the field of logic, say, than in ethics) ${ }^{6}$ clearly they also correspond to a normative distribution (Knights and Richards 2003, 222-3). This is further reflected in the hierarchy established by journal rankings, as well as the rankings of departments that such assessments of quality inform. One part of philosophy today succeeds by renewing its claims on the 'hard' values of truth and rationality. It aligns itself with scientific forms of rationality; it models a kind of neutrality that eschews values of plurality, and radical practices of critique. Thus the discipline in neoliberal times - or those who are the discipline's elite partisans - might be said to engage in a process of remasculinisation or what Haslanger (2008) calls the 'hyper-masculine' coding of its forms of knowledge. These are aspects of contemporary disciplinary survival that lay claim to the 'objective' all too neatly; and I would wager that they conveniently coincide with employment practices which secure and re-secure male lineage, all the while under a gender-blind signage.

\section{Market mechanisms and global values}

One way to ask how the nexus of market rationality and prestige-value has impacted on gender relations within disciplinary philosophy in recent times might be to examine the question of a particularly intellectual kind of relation of domination and subordination - Who judges whom? By what right? Bill Readings

\footnotetext{
5 This claim would require further work to substantiate it than I have room for here, but compare my longer discussion in Jenkins (2013). Analysis of the now defunct ERA journal rankings in Australia would provide further evidence; for instance, Hypatia is the only feminist philosophy journal ranked $\mathrm{A}^{*}-\mathrm{a}$ fact that might seem justified by the thought that this is a specialised area of study, until one also discovers that the top 'general journals' fail to publish work by women at appropriate rates, and likewise publish little or no feminist philosophy. Indeed the majority of what they publish is predominantly by male philosophers and on the 'hard' end of the discipline. Compare the list Haslanger (2008) gives of the 'top 20 journals' with the journal rankings produced in Australia under the ERA.

6 Survey data of American Philosophical Association membership supplies evidence here (Haslanger 2009).
} 
$(1996,193)$ tells us that the discourse of 'excellence' arises in a nihilistic vacuum, where we prove unable to answer questions about what the university is for, as the unifying idea of 'culture' comes undone with the waning of the nation-state:

An order of knowledge and an institutional structure are now breaking down, and in their place comes the discourse of excellence that tells teachers and students simply not to worry about how things fit together, since that is not their problem. All they have to do is get on with doing what they always have done, and the general question of integration will be resolved by the administration with the help of grids that chart the achievement of goals and tabulate efficiency.

The sign of this nihilism is extreme tolerance - you may believe what you like in the University of Excellence, 'all is simply fodder for evaluation in terms of excellence itself' (Readings 1996: 192). Yet Readings' view may be overly sanguine about how the power of 'hard' judgment fades in the wake of neoliberal reforms, overlooking the ways in which it continues to be evoked to legitimate relations of power. Certainly there is what he calls a 'de-referentialisation' at work in the discourse of excellence - that is, the inability to say what anything is excellent for, which facilitates the 'use' of excellence to trump all concrete questions of value. But the hypostatising of the idea of 'excellence' can also be achieved by presenting the appearance of neutrality attaching to objectivity, or the situationless integrity of knowledge claims (Kennedy 1990). Readings suggests that if rankings can be produced through a hybrid and arbitrary set of norms, it is primarily because there is no real 'object' - no real university - to apply them to; whereas, I would suggest that the authority of the rankings incorporates both epistemic symbols and established 'benchmark' norms in ways that function to translate contestation into hierarchical compliance (subordination) across multiple dimensions. If 'excellence' is what must be referenced in every interaction and rewarded, it is not only by way of an administrative rationality, but it also feeds off intellectual and epistemic demands for hierarchy. This constellation of university administration, academic hierarchy, and 'hard' judgment vindicates politically subordinating all that can be deemed to make merely relative claims to truth.

The hard/soft distinction can also be read in terms of the dominance of certain kinds of epistemic claim over others; it operates to gender disciplinary areas in alignment with ready-made perceptions of the epistemic credibility or status of disciplinary participants, but also to re-secure entitlements within the field of judgment. The wider audience for such a staging of value as hard or soft belong not just in philosophy but also in the wider institutional context of the neoliberal academy. Where journals are ranked as most significant in the field, and as belonging to the 'hard' not the 'soft' end of the discipline, what is being privileged is the aspect of the discipline more able to establish its 'excellent' credentials under particular and difficult conditions - for instance, to inflect 
its achievements with a quasi-scientific status that has done much to ensure philosophy's success in an academic world which very often values science over the humanities. This corresponds to a devaluing of all sorts of epistemic claims that incorporate a social dimension, including those of feminist theory, readily regarded in the prevailing neoliberal atmosphere as advancing only 'special interests' (Connell 2014). In such a context it is perhaps unsurprising that the important development of feminist critiques of the masculine hegemony lying concealed within ideals of 'pure, disinterested knowledge' has had little impact on the mainstream discipline of philosophy, or indeed that the mainstream has in many areas in fact strengthened the claims to 'objectivity' that feminist critique contested.

Ranking exercises may thus serve to reinforce established status at multiple levels. If global university rankings are to be intuitively plausible they must preserve the hierarchy with which we are already familiar - if Oxford, Cambridge, Harvard, Yale or Princeton were not in the top 10, we would most likely assume something had gone terribly wrong. ${ }^{7}$ Likewise the micro-hierarchies composed of esteem, reputation, respect and so forth, composing some of the key mechanisms and indices of these modes of measurement, will not challenge existing conceptions. Just as the UN produces maps of the world which show, say, the distribution of respect for human rights in the world, these colourcoded schemas of excellence will reveal a world no different from the political contours established in the long history of empire. In these figurations of virtue we will find nothing that differs from visions of enduring hegemony (Davis et al. 2012). Existing patterns of dominance here reaffirm their legitimacy rather than being called into question by the inquiry. To the objective of affirming global hierarchy as such, the technical difficulties of obtaining internationally comparable data, the plurality of standards that might apply, even the highly questionable assumption that English is the only valid language of research, matter little. The globalisation of higher education becomes framed in these rankings as a competition for status and resources between players which will reaffirm the advantages of placing the vast bulk of funding into the hands of the few who are already the richest and best networked. The faculty and students who flow to such highly-ranked institutions may expect to benefit from the prestige accruing to membership in these illustrious institutions. Their movement reconfirms the high value of these centres, even as they may rightly anticipate accruing greater individual advantages to themselves.

7 'The fact is that essentially all of the measures used to assess quality and construct rankings enhance the stature of the large universities in the major English-speaking centres of science and scholarship and especially the United States and the United Kingdom' (Altbach 2006, 3). 
Simon Marginson and Marijk van der Wende (2007: 326) comment that it remains an open question as to 'the extent to which the prestige fostered by rankings is grounded in real differences in HEI quality or merely recycles the status order'. But it is undoubtedly the case that this notion of 'quality' cannot get going without incorporating generous doses of status affirmation concerning the right to judge - and this perhaps in direct proportion to the need to counteract potential scepticism about the capacity to measure what is being 'produced' across a wide range of needs and differences. Thus it is that:

Most systems of rankings tend to emphasise vertical differences between institutions and between nations, differences of power and authority. At the same time, they obscure horizontal differences, differences of purpose and type. Despite the attractions of horizontal diversity in higher education, league tables have a compelling popularity, regardless of questions of validity, of the uses to which the data are put, and of the effects in system organisation. Rankings are easily recalled, as league tables, and have quickly become part of commonsense knowledge of the sector (Marginson and Van de Wende 2007, 326).

There is a pattern here of self-aggrandisement corresponding to the persistent undervaluing and marginalisation of difference. This should remind us of all that feminists have long contended against. What has been their response to these phenomena?

\section{Gender equality in the orbit of 'excellence'}

A recent manifesto demanding equality of opportunity and pay for female academics calls for institutions to declare how many of their professors, top researchers and students are female, and for this gender profiling to enter into the global rankings of quality. This call to arms cites a report from UNESCO detailing how in 2010, just 29 per cent of researchers worldwide were female (Matthews 2012). The aim of getting global rankings to incorporate measures such as the pay gap between men and women and the gender make-up of senior management is in line with the trend of equity activism in the academic sector to advocate to a high degree within the terms offered by the neoliberal framing of the university sector.

Most discussion of gender equality in academia is now driven by the vocabulary and rationale of the market. It evokes the vocabulary of excellence in order to make a range of claims that link economic benefits to gender parity. In this genre, the fact that women leave academia at much higher rates than men, despite rough parity of numbers on average at PhD level - this reflecting amongst other things, generally unsupportive working conditions and a large gender pay gap is taken up in the mainstream advocacy literature as cause for concern primarily 
on the grounds that this leakage clearly reduces the pool of talent on which employers might draw. The League of European Research Universities (LERU) report Women, Research and Universities: Excellence without Gender Bias (LERU 2012), can be taken as exemplary of the argument presently being put in many quarters:

more women than men drop out of research careers, resulting in an underrepresentation of women in leading positions, a loss of talent for society and a lack of diversity in the workplace, each of which presents a potential threat to the search for excellence in research (LERU 2012, 3).

As an aspect of its concern to specify the 'good economic as well as valuebased arguments' (p. 5) that should underpin universities' gender policies, the report cites 'the lack of an appropriate gender dimension in research design, implementation and organisation' as resulting in 'serious flaws with potentially harmful effects, e.g. in medical research, thus limiting scientific excellence, creativity and benefits to society' (p. 3). Indeed, this claim, together with the idea of a leaking 'pool' of talent constitutes the entire underpinning of the proposal made here - that the LERU universities commit to bringing about structural change to increase women's participation, including the earmarking of special funds to support women at critical stages of their careers.

The LERU report, again typically, places much weight in its analysis on forms of bias that are typically 'unconscious' and of inequities typically too small to see, but cumulative in their effects - 'micro-inequities', as Mary Rowe named them (1974). These factors, for which it would be useless to apportion blame, are held to be the major determinants in distorting career outcomes, ultimately to the detriment of both employers and society at large. These factors not only impair judgment of women's true performance, but also have an 'impact on research productivity and are thereby decisive for career prospects' (LERU 2012, 6). It seems to have become important to affirm that these negative outcomes are not the results of any bad intentions, that men and women alike are able to perpetuate them, and thus that the system is in other respects operating properly but requires adjustments of a mechanical more than a political nature if it is to run optimally. Better investment, allowance for periods of reduced productivity, and appropriate incentives will correct the gendered drain of talent.

None of this in any way challenges the norms by which academic activity is conceptualised in market terms; on the contrary, this is a feminism reinvented to match advocacy strategy to the dominant discourses of our time. To assess whether it is likely to be effective is a task beyond the scope of this discussion - certainly it is not at all clear how women in philosophy would benefit if, as I have suggested, success in this area requires a certain distancing from economic goals in favour of laying claim to 'prestige' signifiers. Why invest in women in 
philosophy if one's goal is to increase a pool of talent with clear socioeconomic objectives? Strategically important though this approach is, what it misses is the need for critique of some aspects of the gendered shape of the neoliberal academy that I have been stressing in the preceding discussion; for instance, how the vocabulary of excellence presumes well-established fields of knowledge into which, at best, women might enter, and to which they might contribute, only as bearers of 'talent' flowing into an existing pool of knowledge.

Contrast the picture drawn by Alison Wylie, a philosopher of science, who argues not simply that we are failing to draw on resources, or that we may be inadvertently overlooking talent - thus not being as 'excellent' as we might otherwise be - but that 'gender inequities can create a cascade of content effects that raise serious questions about the epistemic integrity of a field' (Wylie 2012, 67). Her argument here goes well beyond the idea that we are losing out on some valuable contributors to well-established fields of inquiry to examine precisely the question of how 'epistemic integrity' is constituted. Elaborating the claims of feminist standpoint theory, she argues that disrupting established models of epistemic credibility in view of bringing to light their social coordinates is a key stake in achieving a gender equity that itself has epistemic dimensions. The economic factors that establish the language of excellence as the horizon of judgment, are displaced here to make room for demanding critical engagement with the modes of social organisation that provide legitimation to our epistemic practises. These, she argues $(2012,67)$, must take serious account of both the gendered modes of knowledge transmission (including factors of influence, reputation, resourcing) and production as elements in thinking about how rights of judgment are secured:

this suggests that the ratification of empirical and theoretical results, as knowledge claims we can trust, must be informed by a systematic assessment of how well the epistemic resources of diverse situated epistemic agents have been incorporated into their adjudication; social-cognitive norms of community practice must bring a critical standpoint perspective to bear on the processes of knowledge production if they are to be epistemically credible.

Where the Report cites an 'unconscious bias' in judging women's performance, for which, as is common in the psychological literature, no further account is given (it seems to be considered sufficient merely to evidence the phenomenon itself), Wylie cites 'testimonial injustice' - linked to the devaluation of women as epistemic agents, capable of giving credible accounts. Here the difference is that Wylie intends to reveal an epistemic issue at the very core of knowledge transmission and reception that reflects how seeing or hearing what one wants to (in 'biased' ways) is secured within relations of power that facilitate the 'ubiquitous partiality of social science' $(2012,55)$. Her claims run in the opposite direction to the prevailing 'excellence'-based accounts by focusing her 
critical sights precisely on the problems inherent in the hierarchical ordering of knowledge claims conjoint with the hierarchies of knowers, as these work together to produce profound 'blind spots'. It is less that bias operates on a case-by-case basis than that ruling practices are generally invisible to those who "operate "centre stage", who benefit from the status quo, and who largely define the agenda of the social sciences' (Wylie 2012, 50).

The two agendas of feminist critique do converge at certain crucial points. Both advocate to: 'create gender excellence in research through building inclusive scholarly communities in which men and women contribute equally at all levels of decision making, policy and defining and carrying out research' (Wylie 2012, 11, citing Schiebinger and Schraudner 2011).

The LERU Report argues that the socioeconomic impacts of failing to factor gender into research implementation disadvantage women, insofar as knowledge of their specific needs is less likely to be met - medicine being the paradigm case. In the context of the Report, however, this is translated as the idea that women bring more perspectives to bear, and its evident implications centre on the paradigm of medial science that functions in a privileged way throughout to bolster the argument that absent women's participation, we may miss something important - women's specific bodily differences no less! Despite all that is valid in this concern, it problematically limits the vistas by which we might take the measure of the epistemic advantages involved in challenging existing practice, these considered less perhaps as indexed to the project of including more women, but instead more usefully thought of as limiting the hegemony of the masculine.

A 'critical standpoint perspective' precisely does not hold that women need to be included because of the additional perspectives they bring by being women. Such identity-based claims for the value of women's scholarship has indeed led many women to reject an association with feminist perspectives, and with good reason, for the equation of the 'value' of work with originating in and elaborating a particular perspective, as we have seen, makes it particularly vulnerable to denigration within the 'excellence' economy of claims-making - it becomes a 'special interest', and is inflected from the beginning with the disabling connotations of bias. Wylie, however, helps show a different strategy from the one that, by making identity-based claims for including women's perspectives, would risk contributing to the marginalisation of women's work, and relegation to the 'soft' end of the spectrum of knowledge; for she is advocating something more disruptive than 'inclusion of diversity' or an additive model of bringing differently situated perspectives to bear. But she can do so only by reopening sociopolitical frameworks for thinking about gender equity as integrally bound up with epistemic values at the level of the ratification of credibility, over against the socioeconomic framework appealed to in the LERU Report. The issue Wylie is pressing on in her revision of the key claims of standpoint theory 
is how a mismatch between experience and theory becomes a provocation to question and how marginalised perspectives thus need to be incorporated into good science, not because they supplement or correct oversights, but because at the level of the ratification of empirical and theoretical results, they establish a practice of transformative criticism.

This practice, I think, directly addresses the problem inherent in global ranking exercises, which I suggested incorporate generous doses of status affirmation concerning the right to judge in order to counteract legitimate scepticism about the capacity to measure in what is irreducibly a socio-politically constituted field, comprising a wide range of incommensurable needs and differences. On this account, mainstream research tends to reiterate bias when it fails to be questioned by contesting prevailing epistemic hegemony, but this claim runs profoundly against the models of excellence in academic practise, as they are currently being fostered by an irreducibly sociopolitical, pseudo-market rationality. Wylie's account of feminist standpoint theory suggests a model of knowledge acquisition that would seem to require us to encounter and show humility with respect to difference, for epistemic reasons, because it is this that might challenge us to think again. As such, perhaps it promises a very different model of the global university, and the place of philosophy within it, from the one I sketched out above. 
This text is taken from Through a Glass Darkly: The Social Sciences Look at the Neoliberal University, edited by Margaret Thornton, first published 2014, this version 2015 by ANU Press, The Australian National University, Canberra, Australia. 